\title{
Synthesis of $\pi$-Extended Thiele's and Chichibabin's Hydrocarbons and Effect of the $\pi$-congestion on Conformations and Electronic States
}

\author{
Tomohiko Nishiuchi, ${ }^{*[a, b]}$ Seito Aibara, ${ }^{[a]}$ Hiroyasu Sato, ${ }^{[\mathrm{c}]}$ and Takashi Kubo* ${ }^{[a, b]}$ \\ [a] Department of Chemistry, Graduate School of Science, Osaka University, 1-1 Machikaneyama, Toyonaka, Osaka 560- \\ 0043, Japan.
}

[b] Innovative Catalysis Science Division, Institute for Open and Transdisciplinary Research Initiatives, (ICS-OTRI), Osaka University, Suita, Osaka 565-0871, Japan

[c] Rigaku Corporation, 3-9-12 Matsubara, Akishima, Tokyo 196-8666, Japan

KEYWORDS. Biradicaloid, Molecular Dynamics, $\pi$-congestion, Triplet, Mechanochmistry

\begin{abstract}
The biradicaloid of Chichibabin's hydrocarbon exits in a unique thermal equilibrium between closed-shell singlet and open-shell triplet forms. Conceptually, the incorporation of non-planar aromatic groups, such as anthraquinodimethane (AQD), in these species could bring about stabilization of the individual singlet and triplet spin biradicaloids by creating a high energy barrier for conformational interconversion between folded (singlet) and twisted (triplet) forms. Moreover, this alteration could introduce the possibility of controlling spin states through conformational changes induced by chemical and physical processes. Herein, we report the preparation of AQD containing, $\pi$-extended Thiele's (A-TH) and Chichibabin's (A-CH) hydrocarbons, which have highly $\pi$ congested structures resulting from the presence of bulky 9-anthryl units. The $\pi$-congestion in these substances leads to steric frustration about carbon-carbon double bonds, and creates flexible dynamic motion with a moderate activation barrier between folded singlet and twisted triplet states. These constraints make it possible to isolate the twisted triplet state of A-CH. In addition, simple mechanical grinding of the folded singlet of $\mathbf{A}-\mathbf{C H}$ produces the twisted triplet.
\end{abstract}

\section{INTRODUCTION}

In 1986, Montgomery and co-workers solved the long standing paradox about the nature of Chichibabin's hydrocarbon $(\mathrm{CH}),{ }^{[1,2]}$ which is composed of two triphenylmethyl (trityl) radical units (Figure 1a) ${ }^{[3,4]}$ Magnetic susceptibility measurements showed that this hydrocarbon exists in a singlet spin state ${ }^{[5]}$ and that no thermally excited triplet state signal but only a doublet signal is observed in the ESR spectrum. ${ }^{[6-9]}$ This phenomenon was explained by using the concept that the hydrocarbon is a "biradicaloid", having a structure in which two unpaired electrons weakly interact through an almost planar quinoid skeleton. This property leads to thermal equilibrium between singlet and triplet states that are separated by a small energy difference $\left(\Delta E_{\mathrm{S}-\mathrm{T}}\right)$ of $-5.5 \mathrm{kcal} \mathrm{mol}^{-1}$, and unusual carboncarbon distances that are halfway between single and double bond values (Figure 1a). Based on this seminal effort, many aromatic biradicaloids have been synthesized and their unique optical and magnetic properties have been elucidated. ${ }^{[10-23]}$ Now, more than 35 years after Montgomery's achievement, the chemistry of biradicaloids still attracts great attention.

Recently, the concept of biradicaloid has been extended to non-planar aromatic systems such as overcrowded ethylenes (OCEs). ${ }^{[24-28]}$ While planar biradicaloids undergo rapid thermal equilibrium between singlet and triplet states in the absence of an attending conformational change, non-planar biradicaloids embedded with anthraquinodimethane (AQD) groups undergo large conformational changes between folded closed-shell singlet and twisted open-shell triplet forms. $\mathrm{Wu},{ }^{[29,30]}$ Campos, ${ }^{[11]}$ Suzuki,,${ }^{[32,33]}$ Campaña, ${ }^{[34]}$ Sun,${ }^{[35]}$ and we ${ }^{[36]}$ have described various AQD-based non-planar biradicaloids which incorporate diarylmethyl, fluorenyl, dihydrodimethylanthryl (DMA), dibenzosuberenyl (DBS) and nanohoop units (Figure 1b). The most important feature of diradicaloids, in which interconversions between singlet and triplets states are associated with large conformational changes, is that singlet-triplet interconversion can be controlled and the triplet state is potentially isolable. However, experimental detection of the triplets, for example by using ESR spectroscopy, is often unsuccessful in these systems because the triplet state conformer has a much higher energy than that of the singlet state conformer and the thermal activation barrier for the interconversion is low. Only Suzuki ${ }^{[33]}$ and $\mathrm{we}^{[36]}$ have gained definitive evidence of triplet states through detection of zero-field splitting in ESR spectra of species generated by trapping in a matrix after heating and by photoisomerization in solution, respectively. However, isolation of triplet state conformers under ambient conditions, and the observation of conformational switching between singlet and triplet state forms remain challenging.

In the study described below, we have designed a new family of the AQD-based non-planar biradicaloids, which possess per-dibenzo $\pi$-extended forms of Thiele's (A-TH) and 
(a) Chichibabin's hydrocarbon

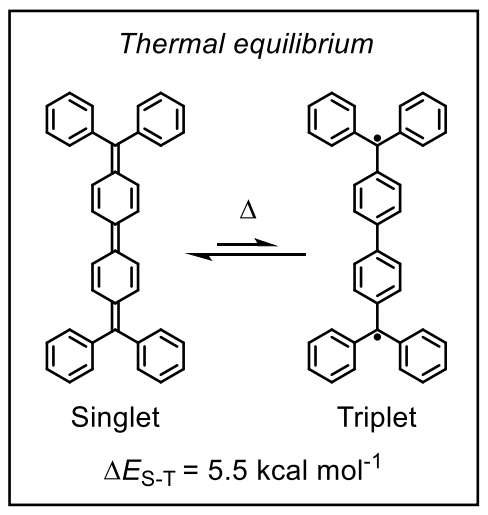

(b) Non-palanr biradicaloid with AQD core

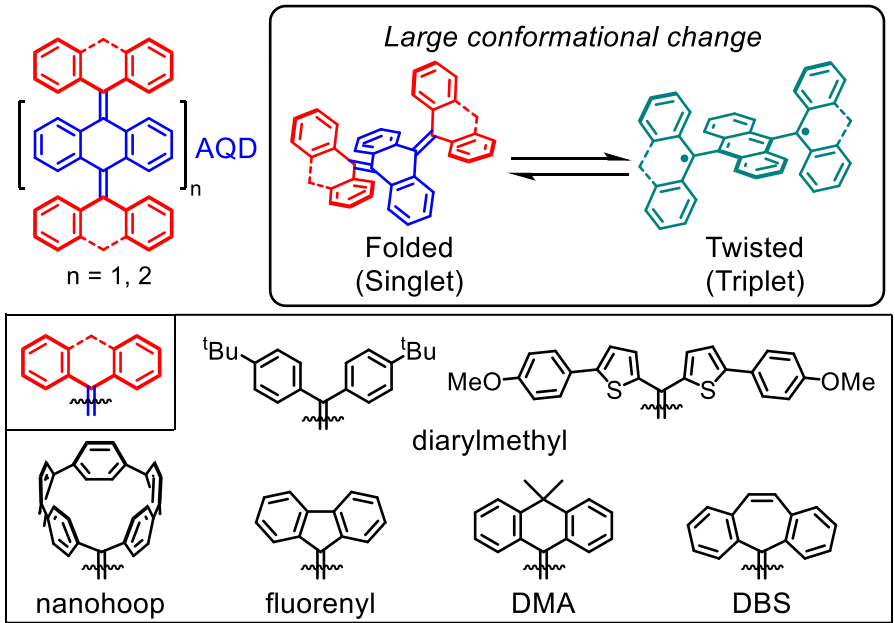

(c) This work: $\pi$-extended Thiele's and Chichibabin's hydrocarbons

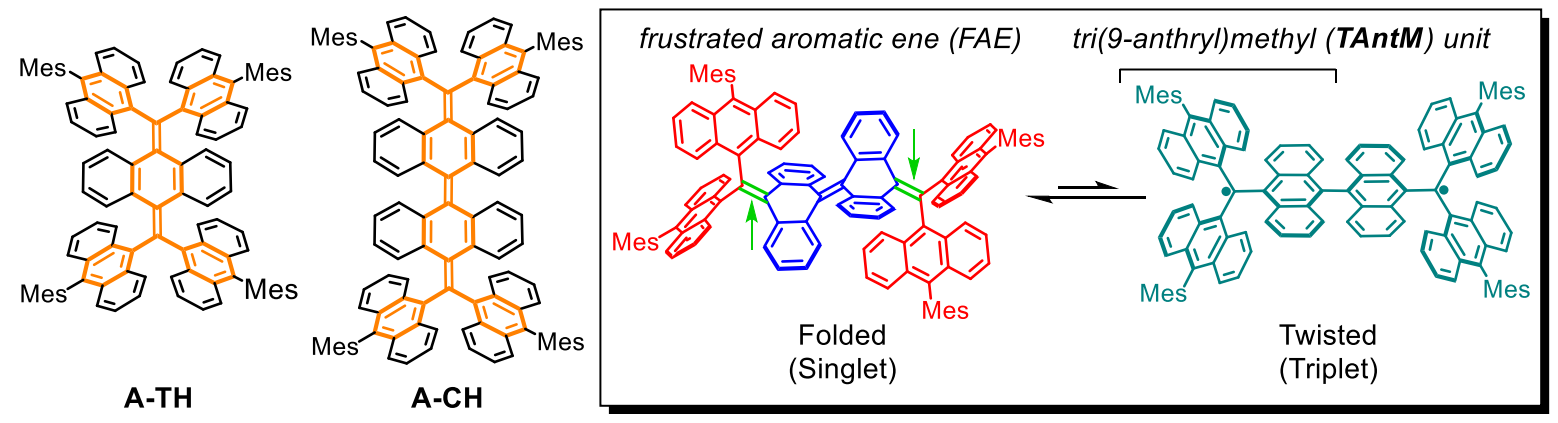

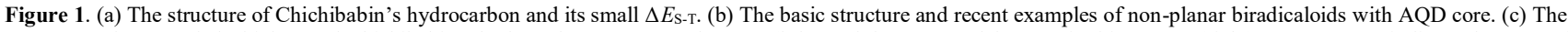
structures of $\pi$-extended Thiele's and Chichibabin's hydrocarbons A-TH and A-CH (left), and the structural features in this system (right).Green arrows indicate the parts of FAE.

Chichibabin's (A-CH) hydrocarbon (Figure 1c). Introduction of di(9-anthryl)methyl units at the terminal $\mathrm{sp}^{2}$ hybridized carbons of the AQD core in each system gives rise to a highly congested $\pi$-system comprised of two tri(9-anthryl)methyl (TAntM) radical units. ${ }^{[37,38]}$ As a result, highly stable triplet states are expected in the twisted conformers. In contrast, the folded conformers of these substances contain unique OCEs on the terminal $\mathrm{C}=\mathrm{C}$ bonds, which give rise to sterically frustrated aromatic enes (FAEs), and the coexistence of both folded and twisted $\mathrm{C}=\mathrm{C}$ bond. In the current effort, we observed that $\pi$-congestion associated with the anthryl units present in A-TH and A-CH gives rise to unique dynamic behavior in solution. We also observed that A-TH can be isolated in the solid state and shown to exist in an unusual anti-conformation about the AQD-core, which represents an intermediate in the conformational conversion between syn-conformations. Importantly, the triplet state of A-CH can be isolated and unambiguously characterized by using UV-vis-NIR and ESR spectroscopy. Furthermore, owing to the presence of flexible FAEs, the structural change of A-CH from a folded conformer (singlet state) to a twisted conformer (triplet state) can be promoted in solid state by simple mechanical grinding. The unique characteristics of these new biradicaloids were also revealed by using theoretical approaches.

\section{RESULTS AND DISCUSSION Synthesis and dynamic behavior in solution}

The methods used to synthesize A-TH and A-CH are shown in Scheme 1. It is notable that even though the presence of 9-anthryl groups create highly congested environments, these substances are generated with modest efficiencies through one-step Negishi coupling reactions of the perbrominated starting materials 1 and $\mathbf{2}$ with mesityl-substituted anthryl zinc chloride (26\% for A-TH as a red solid or in $72 \%$ for A-CH as a yellow solid).

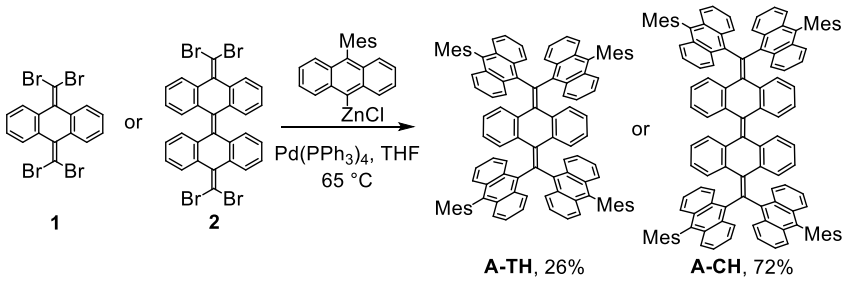

Scheme 1. Route for synthesis of A-TH and A-CH. 
(a)
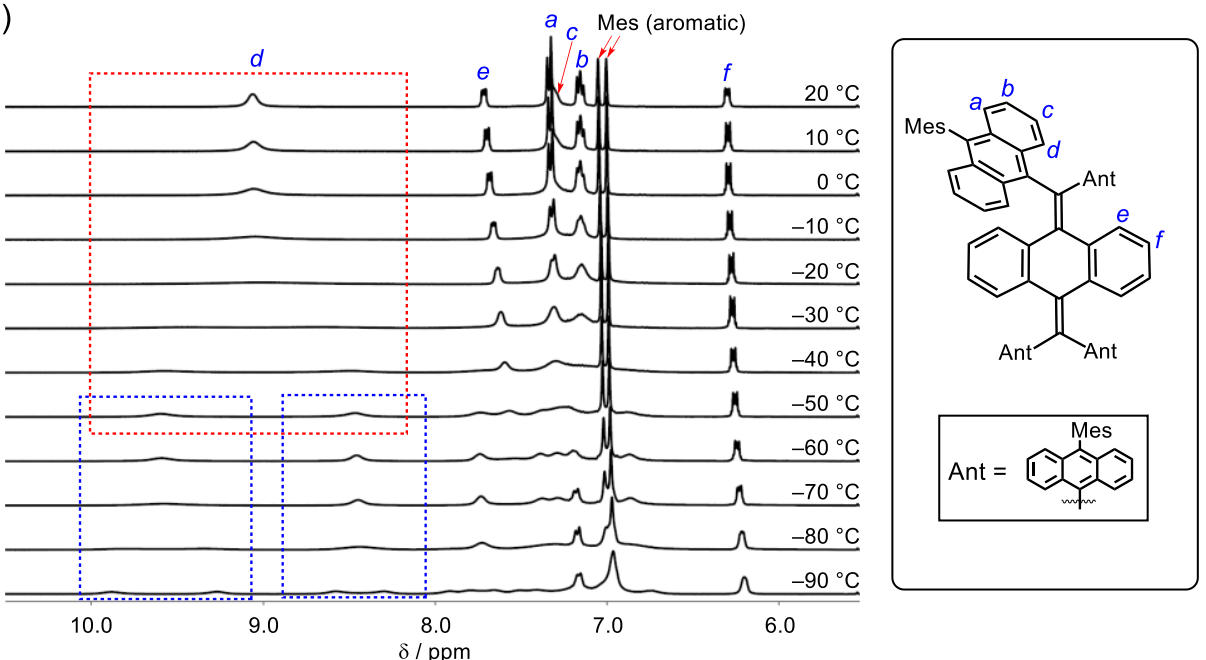

(b) Butterfly flipping

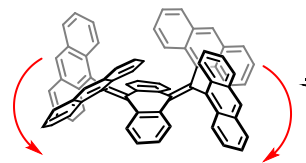

$\Delta H^{\ddagger}=8.49 \mathrm{kcal} \mathrm{mol}^{-1}$

$\Delta S^{\ddagger}=-9.93 \mathrm{cal} \mathrm{mol}^{-1} \mathrm{~K}^{-1} \quad \Delta G^{\ddagger}=11.0 \mathrm{kcal} \mathrm{mol}^{-1}\left(-20^{\circ} \mathrm{C}\right)$ (c) Screw flipping
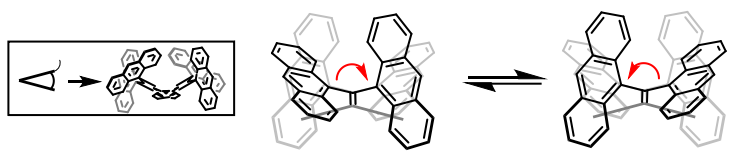

$\Delta H^{\ddagger}=7.07 \mathrm{kcal} \mathrm{mol}^{-1}$

$\Delta G^{\ddagger}=10.2 \mathrm{kcal} \mathrm{mol}^{-1}\left(25^{\circ} \mathrm{C}\right)$

$\Delta S^{\ddagger}=-10.6 \mathrm{cal} \mathrm{mol}^{-1} \mathrm{~K}^{-1} \quad \Delta G^{\ddagger}=9.04 \mathrm{kcal} \mathrm{mol}^{-1}\left(-80^{\circ} \mathrm{C}\right)$

Figure 4. (a) VT ${ }^{1} \mathrm{H}-\mathrm{NMR}$ chart of A-TH from $20{ }^{\circ} \mathrm{C}$ to $-90{ }^{\circ} \mathrm{C}$ in $\mathrm{CD}_{2} \mathrm{Cl}_{2}$. Large coalescence was observed at $d$ proton. The first coalescence occurs from $20{ }^{\circ} \mathrm{C}$ to $-50{ }^{\circ} \mathrm{C}$ (red dash square) and the second coalescence occurs from $-50{ }^{\circ} \mathrm{C}$ to $-90^{\circ} \mathrm{C}$ (blue dash squares). (b) A dynamic motion of butterfly flipping in AQD unit corresponding to the first coalescence, and experimentally determined thermodynamic parameters. (c) A dynamic motion of screw flipping in AQD unit observed from the long-axis direction, corresponding to the second coalescence, and experimentally determined thermodynamic parameters. For (b) and (c), Mes substitution at anthryl units of A-TH are omitted for clarity.

(a)

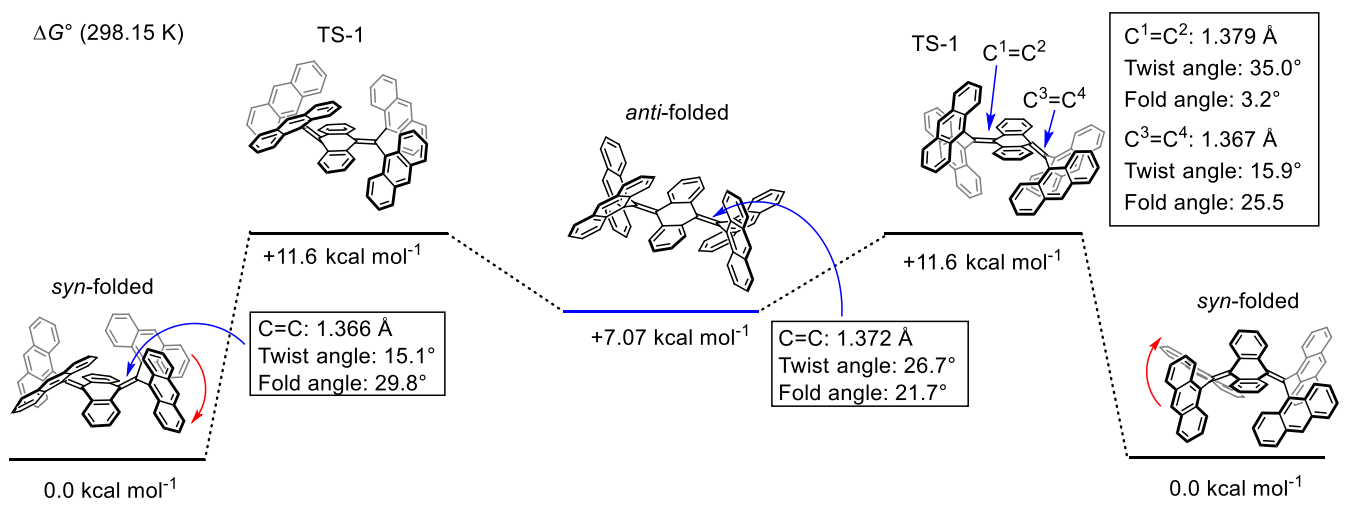

(b)

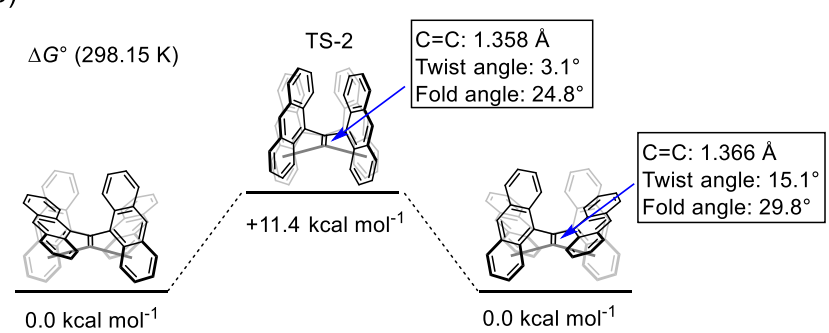

(c)

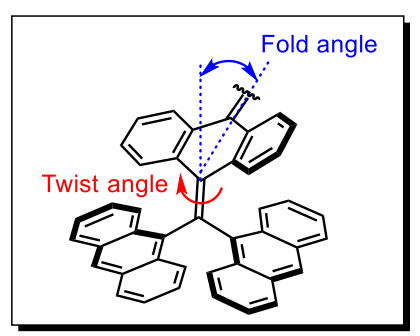

Figure 5. Energy diagrams for the structural interconversion of A-TH' and structural parameters such as C-C bond length and its twist and fold angles at the $\omega$ B97X-D/6$31 \mathrm{G}^{* *}$ level of theory. For the calculations, Mes substitution at anthryl units of A-TH are omitted. (a) Energy diagram for the butterfly flipping of A-TH'. (b) Energy diagram for the screw flipping of A-TH'. (c) The definition of twist and fold angles. 

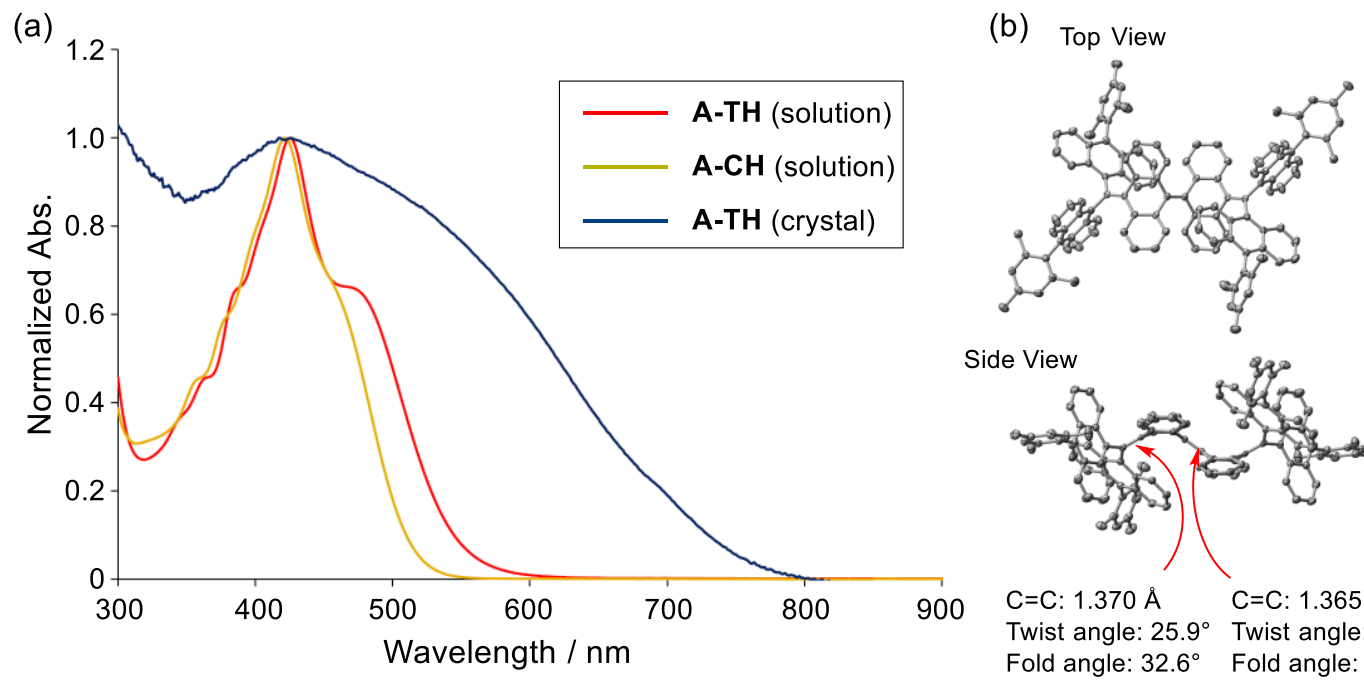

(c) Top View
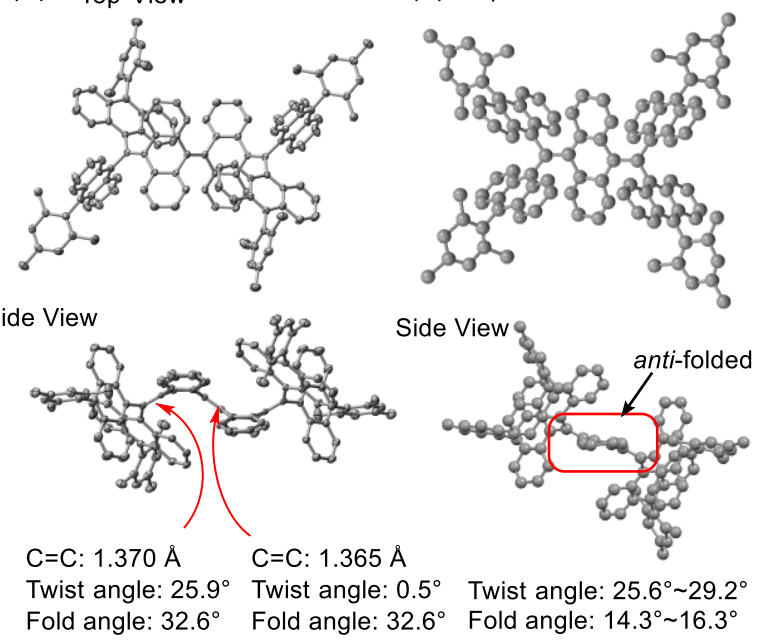

Figure 6. (a) Normalized UV-vis spectra of A-TH and A-CH $\left(\mathrm{CH}_{2} \mathrm{Cl}_{2}\right.$ solution) as well as A-TH (crystalline state). (b) X-ray crystallographic structure of A-CH. Top view (up) and side view (down) with bond length, twist angle, and fold angle of $\mathrm{C}=\mathrm{C}$ bond. (c) $\mathrm{X}$-ray crystallographic structure of $\mathbf{A}-\mathbf{T H}$. Top view (up) and side view (down). Protons are omitted for clarity.

The ${ }^{1} \mathrm{H}-\mathrm{NMR}$ signals of several known AQD-based biradicaloids gradually broaden with increasing temperature probably because the population of triplet state species increases at higher temperatures. ${ }^{[39,40]}$ Thus, it is noteworthy that signals in the solution phase ${ }^{1} \mathrm{H}-\mathrm{NMR}$ spectra of $\mathbf{A}-\mathbf{T H}$ and $\mathbf{A}-\mathbf{C H}$ display the opposite behavior. Specifically, the broad ${ }^{1} \mathrm{H}-\mathrm{NMR}$ signals at $25^{\circ} \mathrm{C}$ become sharper upon heating to $80^{\circ} \mathrm{C}$ (Figure S1, S2). This behavior indicates that a slow conformational change takes place at ambient temperature and no triplet species exist at high temperature. To evaluate this dynamic behavior in solution, low-temperature VT ${ }^{1} \mathrm{H}-\mathrm{NMR}$ experiments were conducted. In Figure $4 \mathrm{a}$ are shown the low magnetic field (5.5-10.5 ppm) regions of ${ }^{1} \mathrm{H}-\mathrm{NMR}$ spectra of A-TH at temperatures between -90 and $20^{\circ} \mathrm{C}$. The position of protons for A-TH were assigned by using 2D-NMR (Figure S3, S4). Inspection of the spectra show that upon cooling the broad signal for anthracene ring proton $d$ at $9.1 \mathrm{ppm}$ broadens and at $-40^{\circ} \mathrm{C}$ separates into two signals at $8.5 \mathrm{ppm}$ and $9.6 \mathrm{ppm}$. In addition, the two newly formed peaks separate further at $-90^{\circ} \mathrm{C}$. The VT-NMR results indicate that two dynamic motions of A-TH occur in solution. The thermodynamic parameters $\left(\Delta H^{\ddagger}, \Delta S^{\ddagger}\right.$, and $\left.\Delta G^{\ddagger}\right)$ for these motions determined by using curve-fitting analysis of the signals for proton d (Figure S5), are given in Figure 4b-c. The dynamic motion corresponding to first ${ }^{1} \mathrm{H}-\mathrm{NMR}$ peak coalescence is associated with butterfly flipping of the AQD core and the second coalescence corresponds to screw flipping of the di(9-anthryl)methyl units around the $\mathrm{C}=\mathrm{C}$ bond. The $\Delta G^{*}$ values associated with these respective processes were determined to be $11.0 \mathrm{kcal} \mathrm{mol}^{-}$ ${ }^{1}\left(-20{ }^{\circ} \mathrm{C}, T_{\mathrm{C}}\right)$ and $9.04 \mathrm{kcal} \mathrm{mol}^{-1}\left(-80{ }^{\circ} \mathrm{C}, T_{\mathrm{C}}\right)$. To gain deeper insight, DFT calculations for this structural change were also performed using A-TH' in which the Mes substituents are absent (Figure 5). The results show that the $\Delta G^{\ddagger}$ to reach the stepwise pathway for butterfly flipping is $+11.6 \mathrm{kcal} \mathrm{mol}^{-1}$, which is in good agreement with the experimental result. ${ }^{[41]}$ Also, the anti-folded conformer has an energy of $+7.07 \mathrm{kcal} \mathrm{mol}^{-1}$ that is higher than that of the $s y n$-folded conformer and the activation barrier to the $s y n$-folded conformer is $4.53 \mathrm{kcal} \mathrm{mol}^{-1}$.
Therefore, in solution, detection of the anti-folded conformer is not possible by using NMR techniques owing to its very low population caused by the rapidly occurring conformational change. For screw flipping through TS-2 the $\Delta G^{\ddagger}$ was found to be $+11.4 \mathrm{kcal} \mathrm{mol}^{-1}$, which is also consistent with the experimental result. In the calculated $s y n$-folded conformer, a $\mathrm{CH}-\pi$ interaction exists between adjacent large anthryl units (Figure S6). This interaction stabilizes the $s y n$-folded conformer, resulting in an increase in the activation barrier for screw flipping.

In contrast, low temperature VT-NMR results for A-CH, are highly complicated owing to the high flexibility of the system in solution. Although signal broadening was observed, quantitative determination of the thermodynamic parameters is difficult due to the presence of many overlapping broad signals (Figure S7). However, as discussed below, we can conclude that the change from the folded to the twisted conformer does not occur at low temperatures due to the high activation barrier.

\section{UV-vis, X-ray structure, CV, and ESR spectra}

The UV-vis spectra of A-TH and A-CH, displayed in Figure 6 , contain intense absorption bands with respective maxima at $425 \mathrm{~nm}\left(\varepsilon=4.12 \times 10^{4} \mathrm{~cm}^{-1} \mathrm{M}^{-1}\right)$ and $420 \mathrm{~nm}\left(\varepsilon=5.05 \times 10^{4}\right.$ $\left.\mathrm{cm}^{-1} \mathrm{M}^{-1}\right)$. Even though the structure of A-CH contains a more extended $\pi$-system than does A-TH, its absorption-edge occurs at shorter wavelength, which is confirmed using TD-DFT calculations (Figure S8, S12).

The structures of A-TH and A-CH in the crystalline state were determined by using X-ray crystallographic analysis. In agreement with theoretical calculations, the crystalline state structure of A-CH possesses a folded conformation (Figure 6b). The bond lengths of the central and terminal $\mathrm{C}=\mathrm{C}$ bonds were found to be $1.365 \AA$ and $1.370 \AA$, respectively, which are normal. The frustrated aromatic ene (FAE) moiety in A-CH contains a highly deformed $\mathrm{C}=\mathrm{C}$ bond with a large twist angle $\left(25.9^{\circ}\right)$ and folded AQD core $\left(32.6^{\circ}\right)$. 

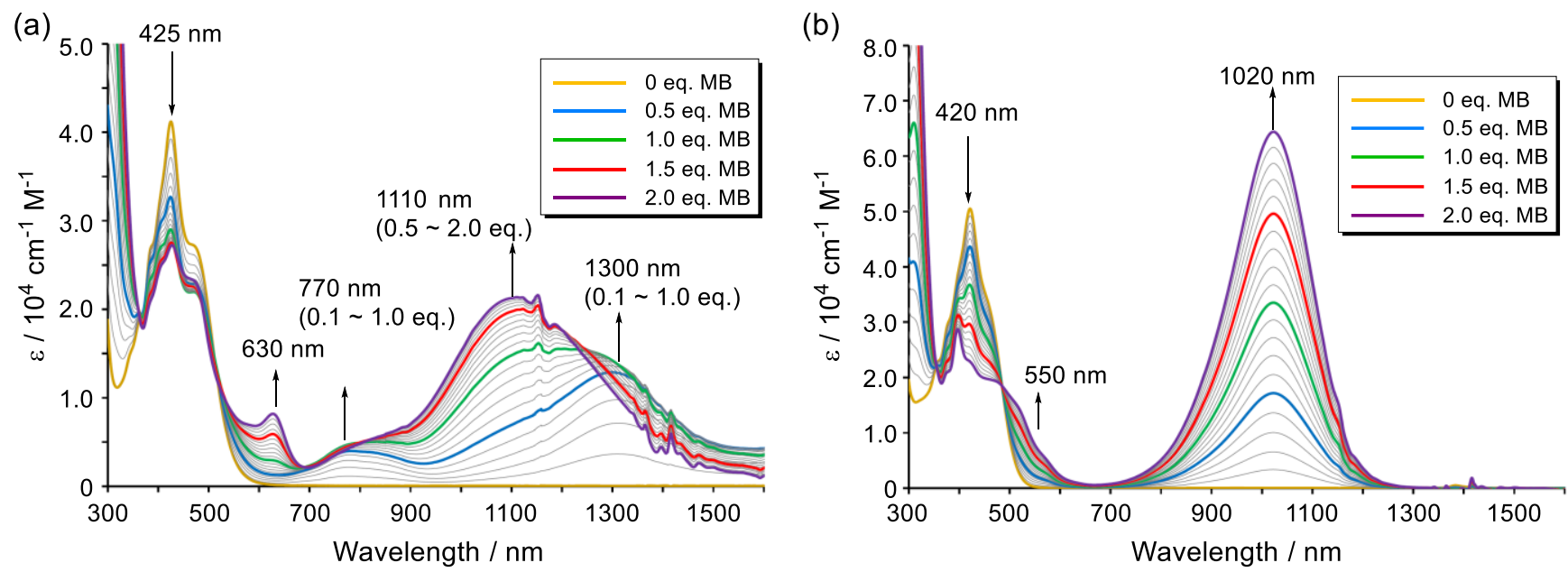

Figure 7. UV-vis-NIR chemical oxidative titration using $\mathrm{MB}$ (added at 0.1 eq. each) in $\mathrm{CH}_{2} \mathrm{Cl}_{2} / \mathrm{MeCN}$. (a) A-TH with $\mathrm{MB}$ from 0 eq. to 2.0 eq. (b) A-CH with $\mathrm{MB}$ from 0 eq. to 2.0 eq.

(a)

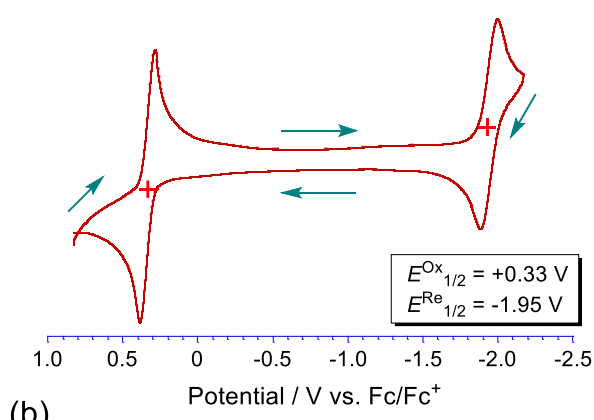

(b)

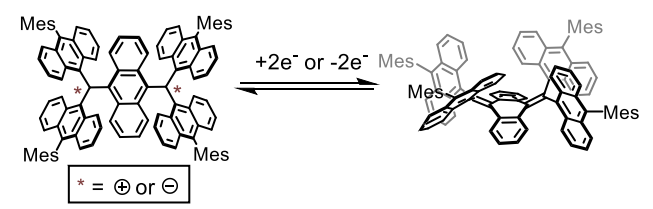

(c)

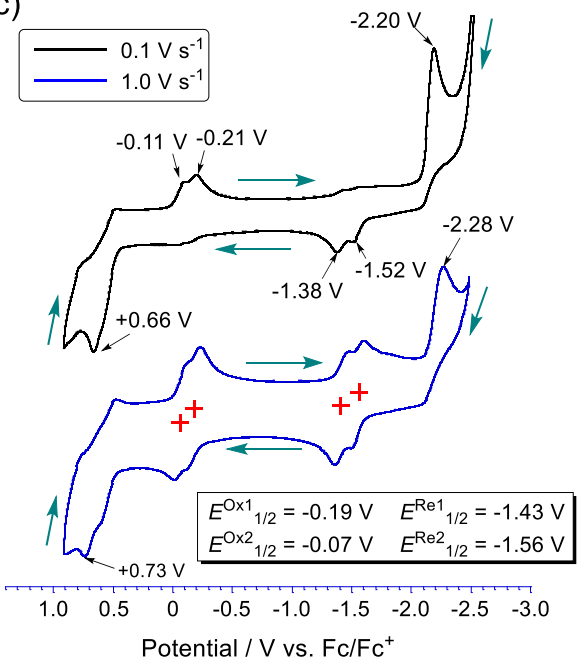

(d)

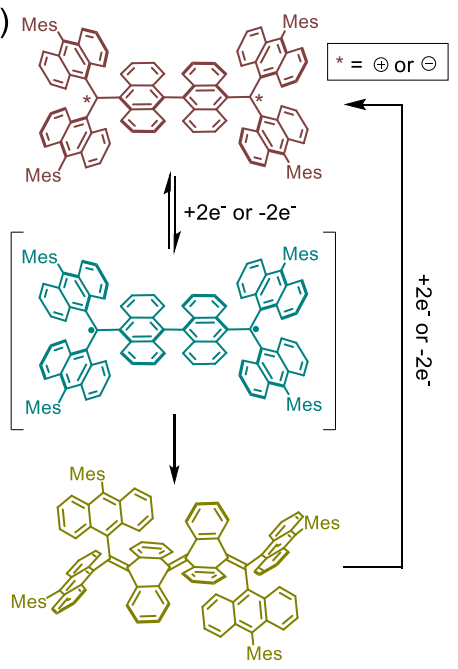

Figure 8. (a) $\mathrm{CV}$ of $\mathbf{A}-\mathbf{T H}\left(0.1 \mathrm{M}^{\mathrm{n}} \mathrm{Bu}_{4} \mathrm{NPF}_{6}\right.$ in $\mathrm{CH}_{2} \mathrm{Cl}_{2}$, scan rate $\left.=0.1 \mathrm{~V} \mathrm{~s}^{-1}\right)$. Green arrows indicate the scan direction. (b) Conformational change of $\mathbf{A}-\mathbf{T H}$ druing the oxidation/reduction processes. (c) $\mathrm{CV}$ of $\mathbf{A}-\mathbf{C H}\left(0.1 \mathrm{M}^{\mathrm{n}} \mathrm{Bu}_{4} \mathrm{NPF}_{6}\right.$ in $\mathrm{CH}_{2} \mathrm{Cl}_{2}$ ). Scan rate $=0.1 \mathrm{~V} \mathrm{~s}^{-1}$ (black line) and $1.0 \mathrm{~V} \mathrm{~s}{ }^{-1}$ (blue line). Green arrows indicate the scan direction. (b) Conformational change of $\mathbf{A}-\mathbf{C H}$ druing the oxidation/reduction processes.

On the other hand, A-TH in crystalline state has an antifolded conformation, which corresponds to the higher energy intermediate in the conformational interconversion (Figure 6c). The reason for this might lie in the presence of intermolecular interactions between the large mesityl substituted anthryl units gain large stabilization energy in crystalline state. The twist and fold angles of $\mathrm{C}=\mathrm{C}$ bonds in A-TH range from $25.6^{\circ}$ to $29.2^{\circ}$ and $14.3^{\circ}$ to $16.3^{\circ}$, respectively. ${ }^{[42]}$ The unique structure of antifolded A-TH in the crystalline state is reflected in its UV-vis absorption spectrum (Figure 6d). Compared with that in solution, the absorption maximum of the crystal is greatly redshifted with its absorption-edge extending to $800 \mathrm{~nm}$. TD-DFT calculations also show the $\mathrm{S}_{0}->\mathrm{S}_{1}$ transition of the anti-folded conformer is $535 \mathrm{~nm}(f=0.3736)$, which is longer than that of the $s y n$-folded conformer ( $497 \mathrm{~nm}, f=0.1905)$ (Figure S9).
Although the anti-folded conformer might be capable of accessing the thermally excited triplet state, the calculated energy difference between triplet and anti-folded conformer of $+9.73 \mathrm{kcal}$ $\mathrm{mol}^{-1}$ is too high to for this to take place under normal experimental conditions (Figure S16).

Next, UV-vis-NIR oxidative titration of A-TH and A-CH using tris(4-bromophenyl)ammoniumyl hexachloroantimonate (magic blue, MB) were performed to generate and investigate their cation states. When 0.1-0.5 eq. $\mathrm{MB}$ in MeCN solution is added to A-TH in $\mathrm{CH}_{2} \mathrm{Cl}_{2}$, a broad absorption peak at $1300 \mathrm{~nm}$ with a shoulder at $1110 \mathrm{~nm}$ forms (Figure 7a). Upon increasing the amount of MB relative to A-TH, the broad peak gradually shifts to shorter wavelength and then an intense peak at 1110 $\mathrm{nm}$ arises after addition of 2.0 eq. of MB. The results are in accord with the expectation that radical cation $\mathbf{A}-\mathbf{T H}^{+}\left(\lambda_{\mathrm{abs}}=1300\right.$ 
$\mathrm{nm})$ is initially formed together with a small amount of dication $\mathbf{A}-\mathbf{T H}^{2+}\left(\lambda_{\mathrm{abs}}=1110 \mathrm{~nm}\right)$, and that the amount of dication A$\mathbf{T H}^{2+}$ increases with increasing amounts of the oxidant MB. The absorption properties of the mono-cation and dication are well reproduced by using TD-DFT calculations (Figure S10, S11). In the case of $\mathbf{A - C H}$, addition of increasing amounts of $\mathrm{MB}$ only results in gradual formation of an intense broad peak at $1020 \mathrm{~nm}$ (Figure 7b), which is similar to that in the spectrum of TAntM cation $\left(\lambda_{\mathrm{abs}}=990 \mathrm{~nm}\right.$, Figure S17). Therefore, chemical oxidation of A-CH involves a disproportionation reaction of the intermediate radical cation $\mathbf{A}-\mathbf{C} \mathbf{H}^{++}$, which directly produces dication $\mathbf{A}-\mathbf{C H}^{2+}$. This is likely the result of the fact that the oxidation potential of radical cation $\mathbf{A}-\mathbf{C} \mathbf{H}^{++}$is lower than that of the folded A-CH (see below).

Cyclic voltammograms (CV) of A-TH and A-CH were measured to assess whether triplet states are generated during the redox processes. The $\mathrm{CV}$ of $\mathbf{A}-\mathbf{T H}$ contains reversible oxidation/reduction waves $E^{\mathrm{Ox}}{ }_{1 / 2}=+0.34 \mathrm{~V}$ and $E^{\mathrm{Re}}{ }_{1 / 2}=-1.90 \mathrm{~V}$ (vs. $\mathrm{Fc} / \mathrm{Fc}^{+}$) (Figure $8 \mathrm{a}$ ). This observation indicates that $\mathbf{A - T H}$ participates in one-step two-electron oxidation/reduction processes and, thus, the twisted dication $\mathbf{A}-\mathbf{T H}^{2+}$ or dianion $\mathbf{A}-\mathbf{T H}{ }^{2-}$ conformer readily reverts to syn-folded neutral counterpart (Figure 8b). Differing from the oxidative titration results described above, a stepwise oxidation process via a radical cation species does not take place. This phenomenon is probably due to small on-site coulomb repulsion. The $\mathrm{CV}$ of $\mathbf{A - C H}$ contains irreversible oxidation/reduction waves at -0.1 to $-0.2 \mathrm{~V}$ and 1.4 to $-1.5 \mathrm{~V}$ (Figure $8 \mathrm{c}$ ). It is noteworthy that increasing the scan rate from 0.1 to $1.0 \mathrm{~V} \mathrm{~s}^{-1}$ reduces the irreversibility, resulting in a $\mathrm{CV}$ that corresponds to a reversible two-step two-electron oxidation/reduction process. Furthermore, the reversible oxidation and reduction potentials $\left(E^{\mathrm{Ox}}{ }_{1 / 2}=-0.19\right.$ and $-0.07 \mathrm{~V}$, $E^{\mathrm{Re}}{ }_{1 / 2}=-1.43$ and $\left.-1.56 \mathrm{~V}\right)$ are very close to those of TAntM radical $\left(E^{\mathrm{Ox}}{ }_{1 / 2}=-0.19, E_{1 / 2}^{\mathrm{Re}}=-1.48 \mathrm{~V}\right)$. Therefore, different from that of A-TH, the twisted dication $\mathbf{A}-\mathbf{C H}^{2+}$ or dianion $\mathbf{A}-$ $\mathbf{C H}^{2-}$ first forms the twisted biradical $\mathbf{A}-\mathbf{C H}^{2 \cdot}$ upon reduction or oxidation, indicating that the activation barrier for conversion of the twisted to the folded conformer is higher in A-CH than in A-TH. (Figure 8d).

These experimental results suggest that, while isolating A-TH in its twisted triplet state will be difficult, it might be possible to form and isolate the twisted triplet $\mathbf{A}-\mathbf{C H}^{2 \cdot}$ by using reduction of the twisted dication $\mathbf{A}-\mathbf{C H}^{2+}$. To explore this possibility, reduction of $\mathbf{A}-\mathbf{C H}^{2+}$ using decamethyl ferrocene (DFc) in $\mathrm{MeCN}$ was carried out at $-40{ }^{\circ} \mathrm{C}$ (Scheme 2). This process formed a powder precipitate having purple-metallic luster that was collected using filtration. The ESR spectrum of the powder in toluene at $-73^{\circ} \mathrm{C}$ contains a characteristic pattern for $\Delta M_{\mathrm{S}}=$ \pm 1 peaks associated with a triplet species (Figure 9a), along with a forbidden half-field transition for $\Delta M_{\mathrm{S}}= \pm 2$ could (Figure $9 b$ ). Using the point dipole approximation, the average spinspin distance was estimated to be $7.33 \AA$, which is shorter than the distance between the spin-center carbons in A-CH (10.03 $\AA$ ) and close to the distance between 10- and 10'-positions of the central dianthryl unit (7.17 $\AA$ ) (Figure 9c, Figure S18). The findings provide unambiguous evidence for the conclusion that the triplet state of twisted $\mathbf{A}-\mathbf{C H}^{2 \cdot}$ can be isolated using precipitation at low temperature.
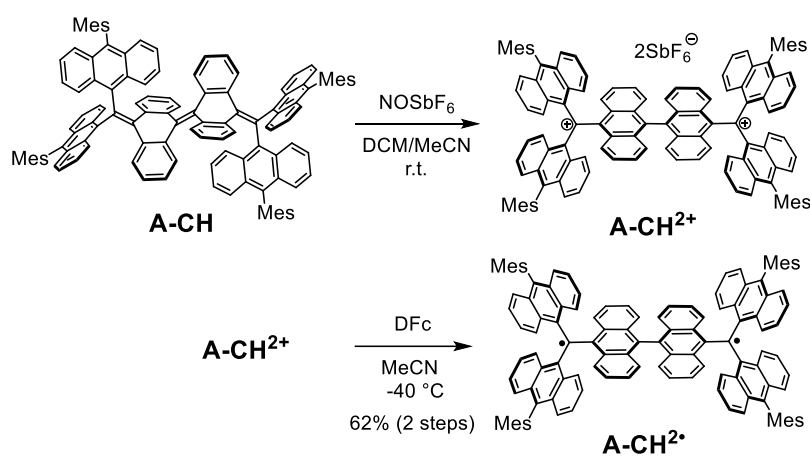

Scheme 2. Route for synthesis of $\mathbf{A}-\mathbf{C H}^{2}$.

(a)

$\Delta M_{\mathrm{S}}= \pm$

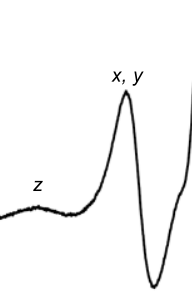

$2 D=14.150 \mathrm{mT}(\mathrm{z}-\mathrm{z})$

$|D|=7.075 \mathrm{mT},|E|=0 \mathrm{mT}, g=2.003$

Average spin-spin distance:

$7.33 \AA$ (point dipole approximation)

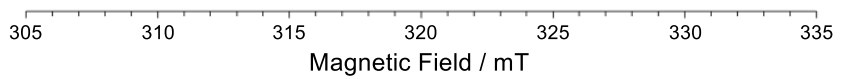

(b)

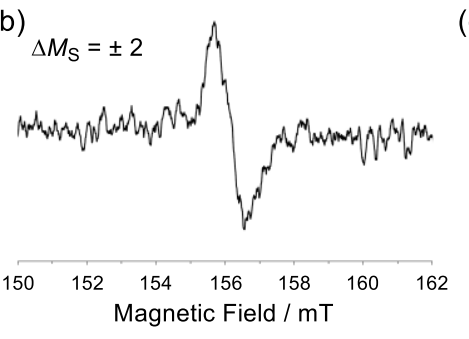

(c)

Figure 9. (a) ESR spectrum of $\mathbf{A}-\mathbf{C H}^{2 \cdot}\left(\Delta M_{\mathrm{S}}= \pm 1\right)$ in toluene at $-73{ }^{\circ} \mathrm{C}$. (b) Forbidden half-field transition $\left(\Delta M_{\mathrm{S}}= \pm 2\right)$ of $\mathbf{A}-\mathbf{C H}^{2}$. (c) Calculated carbon-carbon distances between $\mathrm{sp}^{2}$ carbons and $10,10^{\prime}$-positions of the central dianthryl unit.

Owing to the orthogonal orientation of the central dianthryl unit, the UV-vis-NIR spectrum (Figure 10a) of triplet A$\mathbf{C H}^{2 \cdot}$ at low temperature $\left(-30{ }^{\circ} \mathrm{C}\right)$ is almost identical to that of TAntM radical (Figure S17). Specifically, the spectrum contains an intense peak at $615 \mathrm{~nm}$ and a broad forbidden band from 700-1100 nm. It should be emphasized that the UV-visNIR spectrum was measured at low temperature because the broad band decays quickly at room temperature. To determine thermodynamic parameters for the conversion of triplet $\mathbf{A}-\mathbf{C H}^{2}$ to folded A-CH (Figure S19), decay of the band at $615 \mathrm{~nm}$ at temperatures including $5,0-5,-10$ and $-15{ }^{\circ} \mathrm{C}$ was analyzed. The half-life $t_{1 / 2}$ of $\mathbf{A}-\mathbf{C H}^{2 \cdot}$ was found to be only $21 \mathrm{~s}$ at $5{ }^{\circ} \mathrm{C}$ and $c a .3 \mathrm{~min}$ at $-15^{\circ} \mathrm{C}$. These decay half-lives are considerably shorter than those of the $\pi$-extended $\mathrm{CH}$ reported by $\mathrm{Wu}\left(t_{1 / 2}=\right.$ 

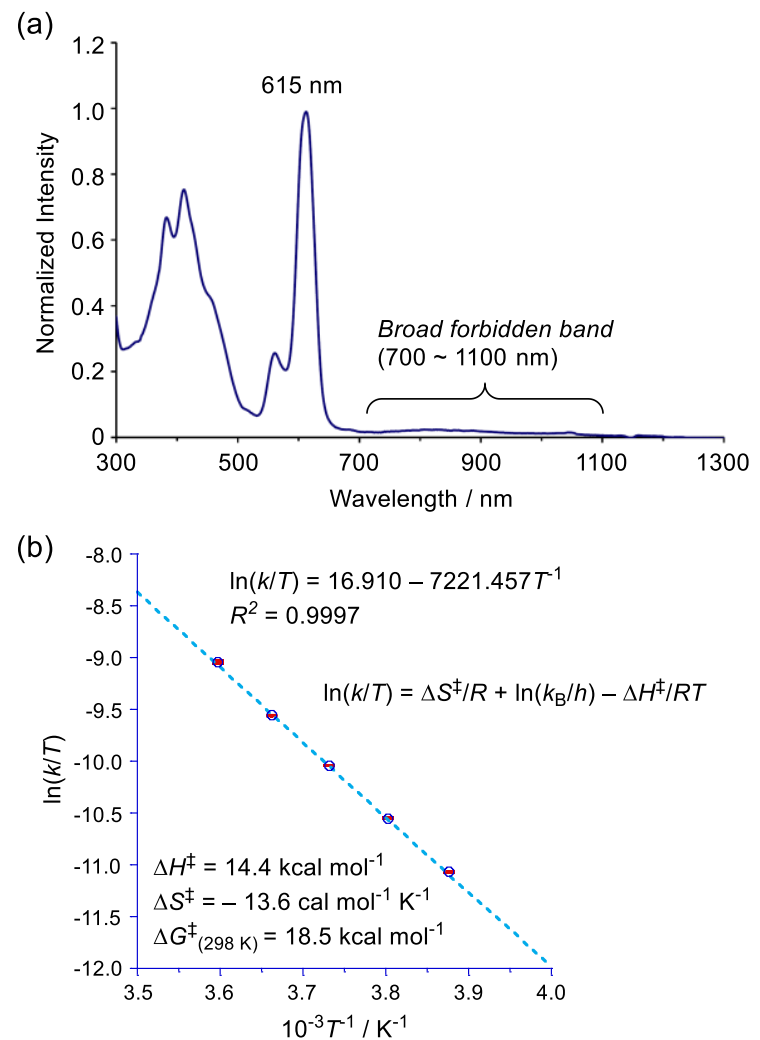

(c) Calculated Gibbs free energy (kcal mol $\left.{ }^{-1}, 25.15^{\circ} \mathrm{C}\right)$

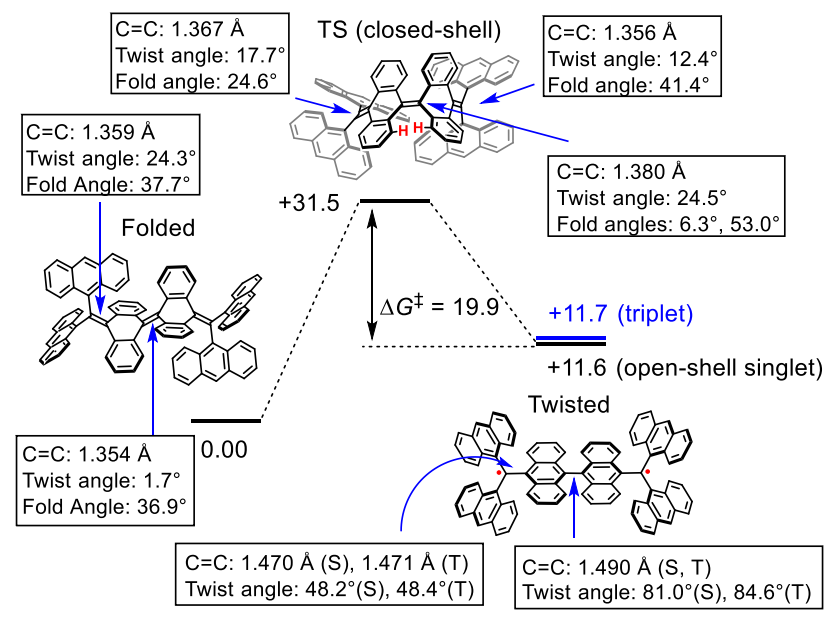

Figure 10. (a) UV-vis-NIR spectrum of twisted $\mathbf{A}-\mathbf{C H}^{2 \cdot}$ in $\mathrm{CH}_{2} \mathrm{Cl}_{2}$ (at $-30{ }^{\circ} \mathrm{C}$ ). (b) Eyring plot of the structural conversion from twisted $\mathbf{A}-\mathbf{C H}^{2 \cdot}$ to folded $\mathbf{A}-\mathbf{C H}$, and its thermodynamic parameters, $\Delta H^{\ddagger}, \Delta S^{\ddagger}$, and $\Delta G^{\ddagger}\left(25^{\circ} \mathrm{C}\right)$. (c) Calculated Gibbs free energies of A-CH' for the structural conversion, and structural parameters such as $\mathrm{C}-\mathrm{C}$ bond length and its twist and fold angles $\left((\mathrm{U}) \omega \mathrm{B} 97 \mathrm{X}-\mathrm{D} / 6-31 \mathrm{G}^{* *}\right)$. For twisted conformer, $\mathrm{S}$ and $\mathrm{T}$ indicate singlet and triplet state, respectively. In TS state, red protons are the most sterically repulsive positions.

$495 \mathrm{~min}$ at $\left.25^{\circ} \mathrm{C}\right) .{ }^{[30]}$ The reason for the difference is not totally clear. Related to this issue is the fact that the TAntM radical itself displays high flexibility in association with anthryl rotation and unpaired electron migration $\left(\Delta E=c a .10 \mathrm{kcal} \mathrm{mol}^{-1}\right) .^{[37]}$ Therefore, the fast decay rate of triplet $\mathbf{A}-\mathbf{C H}^{2 \cdot}$ is consistent with the properties of TAntM radical. The rate constants derived from averages of three measurements at each temperature were used to construct an Eyring plot, which gave the following thermodynamic parameters for conversion of twisted triplet A$\mathbf{C H}^{2 \cdot}$ to folded A-CH: $\Delta H^{\ddagger}=+14.4 \mathrm{kcal} \mathrm{mol}^{-1}, \Delta S^{\ddagger}=-13.6 \mathrm{cal}$ $\mathrm{mol}^{-1} \mathrm{~K}^{-1}$, and $\Delta G^{*}=+18.5 \mathrm{kcal} \mathrm{mol}^{-1}\left(25^{\circ} \mathrm{C}\right)$ (Figure 10b).

DFT calculations on an A-CH' analogue missing Mes substituents were conducted to understand the details of the triplet $\mathbf{A}-\mathbf{C H}^{2 \cdot}$ decay process (Figure 10c). Compared to that of the folded conformer, the relative Gibbs free energy of the twisted conformer having an open-shell singlet state is calculated to be $+11.6 \mathrm{kcal} \mathrm{mol}^{-1}$ and its triplet state energy is +11.7 $\mathrm{kcal} \mathrm{mol}^{-1}$. Thus, $\Delta E_{\mathrm{S}-\mathrm{T}}$ of twisted $\mathbf{A}-\mathbf{C} \mathbf{H}^{2 \cdot} \cdot$ is quite small. The transition state for this conversion, has a quinoidal structure with a closed-shell configuration and a relative free energy of $+31.5 \mathrm{kcal} \mathrm{mol}^{-1}$. Thus, the $\Delta G^{\ddagger}$ for transition of twisted A$\mathbf{C H}^{2 \cdot}$ to folded A-CH' is $+19.9 \mathrm{kcal} \mathrm{mol}^{-1}\left(25^{\circ} \mathrm{C}\right)$, which is in good agreement with the experimental result. Therefore, the results obtained both experimentally and theoretically show that the generation of triplet state from the folded form of $\mathbf{A - C H}$ using thermal activation would be difficult due to the presence of a high barrier. However, the alternative route we developed, using the kinetic trapping method starting with the dication species, serves as an effective method to generate and isolate of twisted triplet state of $\mathbf{A}-\mathbf{C H}^{2}$.

Mechanical-grinding induced triplet state generation of A$\mathrm{CH}$

As mentioned in the introduction above, in the AQD embedded biradicaloids thermal equilibrium between singlet and triplet states is linked to sterically governed, high activation barrier conformational changes between folded and twisted conformers. However, the only approaches developed prior to this study for generating triplet states are thermal activation and light irradiation. Recently, mechanical stress induced $\mathrm{C}-\mathrm{C} \sigma-$ bond cleavage, promoted by grinding, pulling or pressing, ${ }^{[43-51]}$ has been used to produce two monoradical species. This protocol has gained attention for use in mechanical sensors and selfhealing.

Owing to the presence of flexible FAE units in folded A$\mathbf{C H}$, it was anticipated that $\mathrm{C}=\mathrm{C} \pi$-bond cleavage to afford the twisted $\mathbf{A}-\mathbf{C H}^{2}$ in the solid state could be accomplished by grinding. In fact, grinding under air causes the orange color of solid folded A-CH to change to dark green (Figure 11a). Solidstate diffuse-reflection UV-vis-NIR absorption spectroscopy was used to analyze the substance formed by grinding after the color change is complete. Although the intense peak $\lambda_{\mathrm{abs}}=420$ $425 \mathrm{~nm}$, corresponding to the folded A-CH remains in the spectrum, a new sharp peak at $615 \mathrm{~nm}$ is produced by grinding along with a weak broad band from 700 to $1100 \mathrm{~nm}$ that corresponds to triplet $\mathbf{A}-\mathbf{C H}^{2 \cdot}$ (Figure 11b).In addition, the ESR spectrum of a cold $\left(-78{ }^{\circ} \mathrm{C}\right)$ solution formed by grinding of folded $\mathbf{A}-\mathbf{C H}$ contains signals associated with the triplet state of $\mathbf{A}-\mathbf{C H}^{2 \cdot}$ (Figure S20). Judging from these observations, mechanical-grinding of folded A-CH induces triplet generation by promoting $\mathrm{C}=\mathrm{C} \pi$-bond cleavage in solid state. Although determination of the yield for conversion of folded $\mathbf{A}-\mathbf{C H}$ to twisted $\mathbf{A}-\mathbf{C H}^{2 \cdot}$ is 
difficult, the newly devised method enables us to prepare and analyze the triplet state aromatic hydrocarbon under ambient conditions. In addition, being different from the solution state, the absorption the twisted triplet $\mathbf{A}-\mathbf{C} \mathbf{H}^{2 \cdot}$ formed by grinding is persistent for a week at ambient temperature in the solid state (Figure S21).

(a)

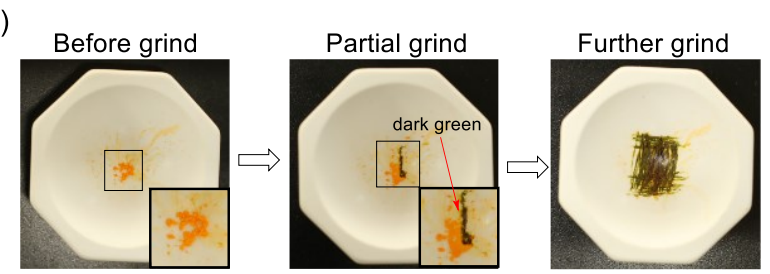

(b)

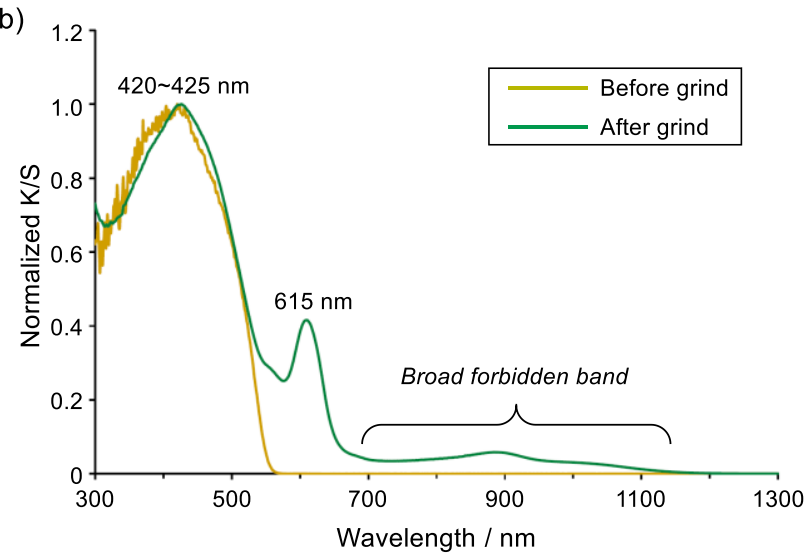

Figure 11. (a) Photoimages of before and after grind of folded A-CH. The color at ground part is changed from orange to dark green. (b) Solid-state diffuse-reflection UV-vis-NIR spectra of before and after grind of folded A-CH.

\section{CONCLUSION}

In the investigation described above, we synthesized the $\pi$-extended versions of Thiele's and Chichibabin's hydrocarbons, A-TH and A-CH, which contain appended 9-anthryl moieties. The presence of flexible FAE components enable both ATH and A-CH to undergo dynamic conformational changes, which can be quantitatively analyzed experimentally and theoretically. The crystalline states of A-TH and A-CH possess quinoidal non-planar structures. A-TH in the crystalline state has a unique unstable anti-folded shape, which is the intermediate in the folded-to-twisted conformational interconversion process. Although A-CH in its ground state exists in a folded conformation as a result of strong intramolecular spin-spin interactions, chemical oxidation experiments revealed that conformational change from folded neutral to twisted dication form can be induced. Reduction of twisted dication $\mathbf{A}-\mathbf{C} \mathbf{H}^{2+}$ with subsequent precipitation at low temperature serves as a convenient method to produce the twisted triplet of $\mathbf{A}-\mathbf{C H}^{2}$. This finding enables elucidation of the fundamental properties of twisted A$\mathbf{C H}^{2 \cdot}$. Furthermore, twisted triplet $\mathbf{A}-\mathbf{C H}^{2 \cdot}$ can be generated by simple grinding of folded A-CH in the solid state. The unique dynamic behaviors of A-TH and A-CH in both solution and solid state originate from the effect of $\pi$-congestion caused by the presence of bulky 9-anthryl units. It is expected that $\pi$-congested multiradicaloids probed in future efforts will exhibit more complicated and interesting natures.

\section{ASSOCIATED CONTENT}

Supporting Information. "This material is available free of charge via the Internet at http://pubs.acs.org." Experimental procedures, characterization of products, spectroscopic data, and theoretical calculations.

Accession Codes. CCDC 2149926 and 2149927 contain the supplementary crystallographic data for this paper. These data can be obtained free of charge via www.ccdc.cam.ac.uk/data_request/cif, or by emailing data_request@ccdc.cam.ac.uk, or by contacting The Cambridge Crystallographic Data Centre, 12 Union Road, Cambridge CB2 1EZ, UK; fax: +44 1223336033.

\section{AUTHOR INFORMATION}

\section{Corresponding Authors}

Tomohiko Nishiuchi - Department of Chemistry, Graduate School of Science, Osaka University, 1-1 Machikaneyama, Toyonaka, Osaka 560-0043, Japan; Innovative Catalysis Science Division, Institute for Open and Transdisciplinary Research Initiatives, (ICS-OTRI), Osa-ka University, Suita, Osaka 565-0871, Japan; orcid.org/ 0000-0002-2113-0731; E-mail: nishiuchit13@chem.sci.osaka-u.ac.jp

Takashi Kubo - Department of Chemistry, Graduate School of Science, Osaka University, 1-1 Machikaneyama, Toyonaka, Osaka 560-0043, Japan; Innovative Catalysis Science Division, Institute for Open and Transdisciplinary Research Initiatives, (ICS-OTRI), Osa-ka University, Suita, Osaka 565-0871, Japan; orcid.org/ 00000001-6809-7396

\section{Authors}

Seito Aibara - Department of Chemistry, Graduate School of Science, Osaka University, 1-1 Machikaneyama, Toyonaka, Osaka 560-0043, Japan

Hiroyasu Sato - Rigaku Corporation, 3-9-12 Matsubara, Akishima, Tokyo 196-8666, Japan

\section{Notes}

The authors declare no conflicts of interest.

\section{Funding Sources}

This study was supported by JSPS KAKENHI Grant-in-Aid for Scientific Research (C) JP20K05475 (T.N.).

\section{ACKNOWLEDGMENT}

Quantum chemical calculations were performed at the Research Center for Computational Science, Okazaki, Japan. T. N. We thank Prof. Shuichi Suzuki (Graduate School of Engineering Science, Osaka University) for acquisition of HR-MS spectra.

\section{REFERENCES}

[1] Tschitschibabin, A. E. Über einige phenylierte Derivate des p, p-Ditolyls. Chem. Ber. 1907, 40, 1810. 
[2] Montgomery, L. K.; Huffman, J. C.; Jurczak, E. A.; Grendze, M. P. The molecular structures of Thiele's and Chichibabin's hydrocarbons. J. Am. Chem. Soc. 1986, 108, 6004.

[3] Gomberg, M. AN INSTANCE OF TRIVALENT CARBON: TRIPHENYLMETHYL. J. Am. Chem. Soc. 1900, 22, 757.

[4] Gomberg, M. Triphenylmethyl, ein Fall von dreiwerthigem Kohlenstoff. Chem. Ber. 1900, 33, 3150.

[5] E. Müller, I. Müller-Rodloff, Magnetochemische Untersuchungen organicher Stoffe. 1. Mitteilung. Zur Frage der Existenz von Biradikalen. Liebig Ann. Chem. 1935, 517, 134.

[6] Brauer, H. -D.; Stieger, H.; Hyde, J. S.; Kispert, L. D.; Luckhurst, ENDOR of biradicals. Molec. Phys. 1969, 17, 457.

[7] Hart, W. J. v.; Oosterhoff, L. J. The E.S.R and electronic absorption spectra of Chichibabin's biradical. Molec. Phys. 1970, 18, 281.

[8] Stieger, H.; Brauer, H. -D. Über das Biradikalparadoxon beim Tschitschibabinschen Kohlenwasserstoff. Chem. Ber. 1970, 103 , 3799.

[9] Popp, F.; Bickelhaupt, F.; Maclean, C. The electronic structure of chichibabin's hydrocarbon. Chem. Phys. Lett. 1978, 55, 327.

[10] Kubo, T.; Shimizu, A.; Sakamoto, M.; Uruichi, M.; Yakushi, K.; Nakano, M.; Shiomi, D.; Sato, K.; Takui, T.; Morita, Y.; Nakasuji, K. Synthesis, intermolecular interaction, and semiconductive behavior of a delocalized singlet biradical hydrocarbon. Angew. Chem., Int. Ed. 2005, 44, 6564.

[11] Konishi, A.; Hirao, Y.; Nakano, M.; Shimizu, A.; Botek, E.; Champagne, B.; Shiomi, D.; Sato, K.; Takui, T.; Matsumoto, K.; Kurata, H.; Kubo, T. Synthesis and Characterization of Teranthene: A Singlet Biradical Polycyclic Aromatic Hydrocarbon Having Kekule Structures. J. Am. Chem. Soc. 2010, 132, 11021.

[12] Kubo, T. Recent Progress in Quinoidal Singlet Biradical Molecules. Chem. Lett. 2015, 44, 111.

[13] Kubo, T. Syntheses and Properties of Open-Shell $\pi$-Conjugated Molecules. Bull. Chem. Soc. Jpn. 2021, 94, 2235.

[14] Abe, M. Diradicals. Chem. Rev. 2013, 113, 7011.

[15] Stuyver, T.; Chen, B.; Zeng, T.; Geerlings, P.; Proft, F. D.; Hoffmann, R. Do Diradicals Behave Like Radicals? Chem. Rev. 2019, 119, 11291

[16] Sun, Z.; Zeng, Z.; Wu, J. Zethrenes, Extended p-Quinodimethanes, and Periacenes with a Singlet Biradical Ground State. Acc. Chem. Res. 2014, 47, 2582.

[17] Zeng, Z.; Shi, X.; Chi, C.; Navarrete, J. T.; Casado, J.; Wu, J. Pro-aromatic and anti-aromatic $\pi$-conjugated molecules: an irresistible wish to be diradicals. Chem. Soc. Rev. 2015, 44, 6578.

[18] Gopalakrishna, T. Y.; Zeng, W.; Lu, X.; Wu, J. From openshell singlet diradicaloids to polyradicaloids. Chem. Commun. 2018, 54, 2186.

[19] Wu, J. Diradicaloids, Jenny Stanford Publishing, 2022.

[20] Chase, D. T.; Rose, B. D.; McClintock, S. P.; Zakharov, L. N.; Haley, M. M. Indeno[1,2-b]fluorenes: Fully Conjugated Antiaromatic Analogues of Acenes. Angew. Chem. Int. Ed. 2011, 50, 1127.

[21] Dressler, J. D.; Haley, M. M. Learning how to fine-tune diradical properties by structure refinement. J. Phys. Org. Chem. $\mathbf{2 0 2 0}$, 33 , e4114.
[22] Shimizu, A.; Tobe, Y. Indeno[2,1-a]fluorene: An Air-Stable ortho-Quinodimethane Derivatives. Angew. Chem. Int. Ed. 2011, 50,6906

[23] Ajayakumar, M. A.; Ma, J.; Lucotti, A.; Schellhammer, K. S.; Serra, G.; Dmitrieva, E.; Rosenkranz, M.; Komber, H.; Liu, J.; Ortmann, F.; Tommasini, M.; Feng, X. Persistent peri-Heptacene: Synthesis and In Situ Characterization. Angew. Chem. Int. Ed. 2021, 60,13853

[24] Agranat, I.; Suissa, M. R. syn, Anti isomerization of 5,5'-Bis5H-dibenzo[a,d]cyclohepten-5-ylidene. Struct. Chem. 1993, 4, 59.

[25] Suzuki, T.; Fukushima, T.; Miyashi, T.; Tsuji, T. Isolation and X-ray Structural Determination of Both Folded and Twisted Conformers of $\mathrm{Bis}\{4 \mathrm{H}, 8 \mathrm{H}-4$-(dicyanomethylene)-benzo[1,2-c:4,5c']bis[1,2,5]thiadiazol-8-ylidene $\}$, an Overcrowded Ethylene with High Electron Affinity. Angew. Chem. Int. Ed. Engl. 1997, 36, 2495.

[26] Biedermann, P. U.; Stezowski, J. J.; Agranate, I. Polymorphism Versus Thermochromism: Interrelation of Color and Conformation in Overcrowded Bistricyclic Aromatic Enes. Chem. Eur. J. 2006, 12, 3345 .

[27] Wentrup, C.; Regimbald-Krnel, M. J.; Müller, D.; Comba, P. A Thermally Populated, Perpendicularly Twisted Alkene Triplet Diradical. Angew. Chem. Int. Ed. 2016, 55, 14600.

[28] Hamamoto, Y.; Hirao, Y.; Kubo, T. Biradicaloid Behavior of a Twisted Double Bond. J. Phys. Chem. Lett. 2021, 12, 4729.

[29] Zhang, X.; Jiang, X.; Zhang, K.; Mao, L.; Luo, J.; Chi, C.; Chan, H. S. O.; Wu, J. Synthesis, Self-Assembly, and Charge Transporting Property of Contorted Tetrabenzocoronenes. J. Org. Chem. 2010, 75, 8069

[30] Zeng, Z.; Sung, Y. M.; Bao, N.; Tan, D.; Lee, R.; Zafra, J. L.; Lee, B. S.; Ishida, M.; Ding, J.; Navarrete, J. T. L.; Li, Y.; Zeng, W.; Kim, D.; Huang, K. -W.; Webster, R. D.; Casado, J. Wu, J. Stable Tetrabenzo-Chichibabin's Hydrocarbons: Tunable Ground State and Unusual Transition between Their Closed-Shell and Open-Shell Resonance Forms. J. Am. Chem. Soc. 2013, 134, 14513.

[31] Yin, X.; Low, J. Z.; Fallon, K. J.; Paley, D. W.; Campos, L. M. The butterfly effect in bisfluorenylidene-based dihydroacenes: aggregation induced emission and spin switching. Chem. Sci. 2019, 10, 10733

[32] Ishigaki, Y.; Hayashi, Y.; Suzuki, T. Photo- and Thermal Interconversion of Multiconfigurational Strained Hydrocarbons Exhibiting Completely Switchable Oxidation to Stable Dicationic Dyes. J. Am. Chem. Soc. 2019, 141, 18293.

[33] Ishigaki, Y.; Hashimoto, T.; Sugawara, K.; Suzuki, S.; Suzuki, T. Switching of Redox Properties Triggered by a Thermal Equilibrium between Closed-Shell Folded and Open-Shell Twisted Species. Angew. Chem. Int. Ed. 2020, 59, 6581.

[34] Jiménez, V. G.; Mayorga-Burrezo, P.; Blanco, V.; Lioveras, V.; Gómez-García, C. J.; Šolomek, T.; Cuerva, J. M.; Veciana, J. Campaña, A. G. Dibenzocycloheptatriene as end-group of Thiele and tetrabenzo-Chichibabin hydrocarbons. Chem. Commun, 2020, 56,12813 .

[35] Li, K.; Xu, Z.; Xu, J.; Weng, T.; Chen, X.; Sato, S.; Wu, J. Sun, Z. Overcrowded Ethylene-Bridged Nanohoop Dimers: Regioselective Synthesis, Multiconfigurational Electronic States, and Global Hückel/Möbius Aromaticity J. Am. Chem. Soc. 2021, 143, 20419. 
[36] Nishiuchi, T.; Ito, R.; Stratmann, E.; Kubo, T. Switchable Conformational Isomerization of an Overcrowded Tristricyclic Aromatic Ene. J. Org. Chem. 2020, 85, 179.

[37] Nishiuchi, T.; Aibara, S.; Kubo, T. Synthesis and Properties of a Highly Congested Tri(9-anthryl)methyl Radical. Angew. Chem. Int. Ed. 2018, 57, 16516.

[38] Nishiuchi, T.; Ishii, D.; Aibara, S.; Sato, H.; Kubo, T. Synthesis, properties and chemical modification of a persistent triisopropylsilylethynyl substituted tri(9-anthryl)methyl radical. Chem. Commun. 2022, DOI: 10.1039/D2CC00548D.

[39] Evaluation of biradicaloids by increasing the ESR intensity upon heating should be carefully conducted because a doublet impurity is often observed, as referred to in [6]-[9].

[40] Recently, $\mathrm{Wu}$ and Isobe reported that ESR measurements of biradicaloid using commercially available $\mathrm{CHCl}_{3}$ causes an unknown ESR signal derived from an aromatic hydrocarbon. Upon heating, the ESR intensity increases as with a biradicaloid, which is misinterpreted as the presence of thermally excited triplet species. see; Li, G.; Matsuno, T.; Han, Y.; Wu, S.; Zou, Y.; Jiang, Q.; Isobe, H.; Wu, J. Fused Quinoidal Dithiophene-Based Helicenes: Synthesis by Intramolecular Radical?Radical Coupling Reactions and Dynamics of Interconversion of Enantiomers. Angew. Chem. Int. Ed. 2021, 60, 10326.

[41] Recently, Suzuki and co-worker reported the structural conversion of AQD derivative via a similar pathway. See; Ishigaki, Y.; Tadokoro, T.; Harabuchi, Y.; Hayashi, Y.; Maeda, S.; Suzuki, T. Anthraquinodimethane Ring-Flip in Sterically Congested Alkenes: Isolation of Isomer and Elucidation of Intermediate through Experimental and Theoretical Approach. Bull. Chem. Soc. Jpn. 2022, 95 , 38.

[42] Due to the large $R_{1}$ value of the X-ray crystal data, we did not discuss the $\mathrm{C}=\mathrm{C}$ bond lengths of anti-folded A-TH.
[43] Beyer, M. K.; Clausen-Schaumann H. Mechanochemistry: The Mechanical Activation of Covalent Bonds. Chem. Rev. 2005, 105, 2921.

[44] Caruso, M. M.; Davis, D. A.; Shen, Q.; Odom, S. A.; Sottos, N. R.; White, S. R.; Moore, J. S. Mechanically-Induced Chemical Changes in Polymeric Materials. Chem. Rev. 2009, 109, 5755.

[45] Black, A. L.; Lenhardt, J. M.; Craig, S. L. From molecular mechanochemistry to stress-responsive materials. J. Mater. Chem. 2011, 21, 1655 .

[46] Ribas-Arino, J.; Mark, D. Covalent Mechanochemistry: Theoretical Concepts and Computational Tools with Applications to Molecular Nanomechanics. Chem. Rev. 2012, 112, 5412.

[47] Li, J.; Nagamani, C.; Moore, J. S. Polymer Mechanochemistry: From Destructive to Productive. Acc. Chem. Res. 2015, 48, 2181.

[48] Willis-Fox, N.; Rognin, E.; Aljohani, T. A.; Daly, R. Polymer Mechanochemistry: Manufacturing Is Now a Force to Be Reckoned With. Chem 2018, 4, 2499.

[49] Imato, K.; Nishihara, M.; Kanehara, T.; Amamoto, Y.; Takahara, A.; Otsuka, H. Self-Healing of Chemical Gels Cross-Linked by Diarylbibenzofuranone-Based Trigger-Free Dynamic Covalent Bonds at Room Temperature. Angew. Chem. Int. Ed. 2012, 51, 1138.

[50] Imato, K.; Ohishi, T.; Nishihara, M.; Takahara, A.; Otsuka, H. Network Reorganization of Dynamic Covalent Polymer Gels with Exchangeable Diarylbibenzofuranone at Ambient Temperature. $J$. Am. Chem. Soc. 2014, 136, 11839.

[51] Nishiuchi, T.; Kisaka, K.; Kubo, T. Synthesis of AnthraceneBased Cyclic $\pi$-Clusters and Elucidation of their Properties Originating from Congested Aromatic Planes. Angew. Chem. Int. Ed. 2021, 60, 5400 . 